\title{
An experimental field approach to parasitism and immune defence in voles
}

\author{
G. A. SCHWARZENBACH ${ }^{1 *}$, D. HEGGLIN ${ }^{2}$, C. STIEGER ${ }^{2}$, P. DEPLAZES ${ }^{2}$ and P. I. WARD \\ ${ }^{1}$ Zoological Museum and ${ }^{2}$ Institute of Parasitology, University of Zürich, Winterthurerstrasse 190, CH-8057 Zürich, \\ Switzerland
}

(Received 18 September 2003; revised 16 November and 15 December 2003; accepted 15 December 2003)

\section{S UMMARY}

The fox tapeworm Echinococcus multilocularis is typically perpetuated in a cycle with red foxes as definitive hosts and various rodent species as intermediate hosts. In this study, foxes were baited with a highly efficient drug against cestodes (praziquantel) in 5 blocks of $1 \mathrm{~km}^{2}$. Voles, Avvicola terrestris, the most abundant intermediate host species, were trapped in the 5 baited blocks and in 5 non-baited control blocks. Baiting the foxes reduced the prevalence of $E$. multilocularis in fox faecal samples in the baited blocks, but voles trapped in the two blocks did not differ in their infection rates. However, voles from the baited blocks had significantly smaller spleen masses and were more likely to be infested with mites than those from the control blocks, possibly reflecting different immunological activities. Our study suggests that the environmental contamination with $E$. multilocularis eggs, and perhaps those of other tapeworms, influences the immune system of the intermediate host species $A$. terrestris in the wild.

Key words: Arvicola terrestris, Echinococcus multilocularis, urban fox, rodent, infection pressure.

\section{INTRODUCTION}

Human Alveolar Echinococcosis, one of the most lethal helminth zoonoses, is caused by infection with the tapeworm Echinococcus multilocularis (Amman \& Eckert, 1995). Red foxes (Vulpes vulpes) are the main definitive hosts of this worm and the source of human infections. Since red fox populations have increased recently in several European countries (Christensen, 1985; Møller-Nielsen, 1990; Breitenmoser et al. 2000), their growing populations, especially in urban areas, may increase health risks for urban citizens.

In Europe, E. multilocularis is typically perpetuated in a cycle including foxes and various rodent species as intermediate hosts (Eckert \& Deplazes, 1999). Adult tapeworms in foxes produce eggs for 1-4 months and these eggs reach the environment in fox faeces (Nonaka et al. 1996). When ingested by an intermediate host, the oncosphere hatches in the gut. It penetrates the intestinal mucosa, enters venous or lymphatic vessels and then develops predominantly in the liver, with subsequent metastasis formation in other sites (see Schantz \& Gottstein, 1986). In the intermediate host, production of protoscoleces takes place within 20-35 days, and infective protoscoleces can be found 40-60 days after infection (Eckert, 1998). A definitive host must ingest metacestodes which contain infective protoscoleces to complete the cycle.

* Corresponding author: Zoologisches Museum, Universität Zürich-Irchel, Winterthurerstrasse 190, CH-8057 Zürich, Switzerland. Fax: +41635 4780. Tel: +41635 4769. E-mail: gioia.schwarzenbach@access.unizh.ch
The most important intermediate hosts of $E$. multilocularis in Europe are Microtus arvalis and Arvicola terrestris (Eckert et al. 2001a). Although foxes prefer small microtine rodents as prey, they switch diet when $A$. terrestris are highly abundant (Weber \& Aubry, 1993). Recent analyses of urban foxes in Zürich found that $A$. terrestris was the most frequent potential intermediate host (Contesse et al. 2004). Little is known about parasite prevalences in intermediate hosts, although compared to prevalences in foxes $(20-60 \%)$, they appear to be low (1-6\%) (Houin et al. 1982; Pétavy \& Deblock, 1983 ; Eckert et al. 2001 b). However, a study in Zürich found prevalences of up to $20 \%$ in $A$. terrestris and in urban foxes during winter, rates as high as $47 \%$ in the urban and $67 \%$ in adjacent recreational areas (Hofer et al. 2000).

The prevalence of $E$. multilocularis in wild foxes can be reduced by regular distribution of baits containing praziquantel, a highly efficient drug against adult cestodes (Schelling \& Frank, 1997; Tackman et al. 2001). Recently, we have demonstrated that the E. multilocularis egg contamination in urban areas can be reduced to very low levels by the manual distribution of anthelmintic baits at monthly intervals. This is even possible within small defined urban patches situated in a highly endemic area (Hegglin et al. 2003). However, little attention has been paid to the role of the intermediate hosts in transmission dynamics, although several studies have indicated its importance (Giradoux et al. 1997; Eckert et al. $2001 a)$.

Studies on the natural life-cycle of the parasite $E$. multilocularis and its transmission dynamics are rare. 
In the framework of an ongoing experimental study (Hegglin et al. 2003) foxes were baited with praziquantel in 5 blocks of $1 \mathrm{~km}^{2}$ and voles from these blocks were compared with voles from 5 non-baited control blocks. If baiting successfully reduced parasite prevalence in foxes, 2 different environmental treatments were created in which the voles were exposed to different infection risks with E. multilocularis, and possibly other tapeworms. We investigated immunological activity by measuring spleen mass. The mammalian spleen is an important component of the immune system; it helps the body to resist parasites (Kopp, 1990), it induces immune responses (Steininger \& Barth, 1999) and an increase in spleen mass occurs in response to infections and passive immunizations (John, 1995; Skarstein, Folstrad \& Liljedal, 2001). In early E. multilocularis infections in the intermediate host, the suppression of larval growth is critical for the final outcome of the disease (Gottstein, 1992), and infected laboratory rodents show marked activation of cell-mediated immunity (e.g. Ali-Khan, 1978b; Fotiadis et al. 1999). During parasite growth, there is a decline in peritoneal lymphocyte, monocyte and eosinophil cell numbers and an increase in spleen mass (Ali-Khan, 1974, 1978a; Devouge \& Ali-Khan, 1983). We also measured the prevalence of ectoparasitic mites, enabling us to examine relationships between infections with different parasites.

MATERIALS AND METHODS

\section{Study site}

The city of Zürich is surrounded by forests and agricultural land. There is a high density of $11 \cdot 2$ foxes per $\mathrm{km}^{2}$ and the urban transmission cycle of the parasite E. multilocularis occurs predominantly in areas adjacent to the city (Deplazes et al. 2002; Gloor, 2002; Stieger et al. 2002). We therefore selected 5 areas near Zürich and marked out within each of these areas 2 blocks of $1 \mathrm{~km}^{2}$ (Fig. 1). One was an experimental block, where baits containing praziquantel were distributed monthly, and the other was a control block. Blocks were allocated to a treatment without prior knowledge. They were arranged so that control and baited blocks alternated geographically. This ensured there was no possibility that baited or control blocks were clumped together; i.e. blocks within a treatment would not have shared a particular infection history (Fig. 1). In particular, we stress that although voles in our study may have been already infected, this would be equally likely for a vole exposed to either of our treatments. We used commercial baits (Impfstoffwerk Dessau Tornau GmbH, Rosslau, Germany), each weighed $13.5 \mathrm{~g}$, and the matrix consisted of Altrofox 91 (Impfstoffwerk Dessau Tornau $\mathrm{GmbH}$ ). This matrix is the same as in the widely used rabies vaccine bait Rabifox

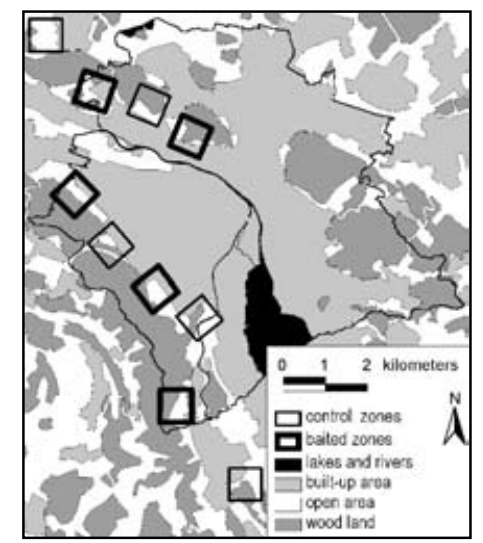

Fig. 1. Study site: City of Zurich and adjacent area.

(Impfstoffwerk Dessau Tornau GmbH). The baits contained $50 \mathrm{mg}$ of the anthelmintic praziquantel (Droncit Bayer AG, Leverkusen, Germany), a highly efficient drug against adult cestodes.

There was a distance of at least 750 meters between an experimental block and a control block, to minimize the chance of individual foxes using 2 study blocks. The blocks all shared similar portions of urban area (1/3) and agricultural landscape and woodland $(2 / 3)$ in a pattern typical for the area.

\section{Anthelmintic treatment of foxes}

Preliminary experiments confirmed the good acceptance of bait items (Hegglin et al. 2004). From April 2000, pellets were distributed monthly in the baited blocks at doses of 50 baits per $\mathrm{km}^{2}$. They were distributed where they were likely to be found by foxes, for example near compost heaps, on a path frequently used by foxes, on a vole tumulus or close to dens (for details see Hegglin et al. 2003).

Faecal samples were collected at least monthly in all blocks. A method of identifying fox faeces was established. Several criteria, such as size, shape and smell of the dung, were used to distinguish fox faeces from dog faeces (Stieger et al. 2002). Only faecal samples collected within a radius of 750 metres from the centre of the study blocks were analysed. This maximized the likelihood that only faeces of territorial foxes living within the blocks were used. $E$. multilocularis was detected by screening samples with a coproantigen ELISA (Em-ELISA) (Deplazes et al. 1999).

\section{Arvicola terrestris}

The A. terrestris trap sites were located mainly on grassland. In every sampling block, one or two grassland patches that showed the highest relative densities of voles were selected (see Giradoux et al. 1995). From May to October 2000, four trapping sessions were conducted on every trap site at around 6 -week intervals. Between 20 and 30 traps were set 
inside vole galleries per trapping session. We used unbaited Topcat traps (Topcat GmbH, Wintersingen, Switzerland). A trapping session was ended if 10 voles were caught. Voles were collected after death and stored individually at $-20{ }^{\circ} \mathrm{C}$. Body weight to the nearest $0.01 \mathrm{~g}$ and body length to the nearest $1 \mathrm{~mm}$, from the tip of the nose to the first vertebra of the tail, were recorded. The presence of ectoparasitic mites (Laelaps species) was recorded by carefully combing the coat against the grain and examining the plastic bag the vole was stored in. At necropsy, the spleen was removed, cleaned of other tissue and weighed to the nearest $1 \mathrm{mg}$. In females, the presence and number of embryos and placental scars was recorded and it was noted whether they were lactating. The liver in particular, but also other organs such as lung, kidney, spleen and reproductive and intestinal tracts, were examined for lesions or irregularities. Metacestodes of E. multilocularis were identified morphologically and by using modified PCR (Dinkel et al. 1998). Identification of lesions caused by other cestodes was based on gross morphology and by comparing hook morphology and length.

\section{Statistics}

Data were analysed using ANCOVA and logistic regression (SPSS 10 PC-Version, 1999). To evaluate the infection rate of foxes in baited and control zones, we pooled the data of faecal samples collected in the two periods from April to June 2000 and from July to October 2000. The small number of faecal samples collected in some months prevented analysis of shorter time-intervals. To evaluate parasite prevalence in voles trapped in the two treatments, we pooled the data from May to June 2000 and from July to October 2000. To reveal effects on a finer timescale, we used 2-month intervals (May and June, July and August, September and October) to carry out further analyses with the vole data. Spleen mass was log transformed. Body length was used as a covariate. Since body length influenced spleen mass significantly, we removed the effects of body length by taking the residuals of a linear regression of transformed spleen mass on body length.

\section{RESULTS}

\section{Prevalence of E. multilocularis in fox faecal samples}

Logistic regression with the factors BAIT (treatment of the foxes), AREA (5 different areas that each included a baited and a control block) and 2 time-periods, SEASON (April to June and July to October) was used to investigate whether baiting the foxes reduced the portion of coproantigen-positive faeces. The proportion decreased during the year (April-June 28.9 $\pm 5 \cdot 2 \%$ vs. July-October $14 \cdot 2 \pm$ $2 \cdot 5 \%$ ) and was lower in baited zones (baited
$14 \cdot 0 \pm 0 \cdot 26 \% v s$. control $26 \cdot 3 \pm 4 \cdot 5 \%$ ) (AREA, Wald $\chi^{2}=6 \cdot 2,4$ D.F., $P=0 \cdot 186$; BAIT, Wald $\chi^{2}=4 \cdot 5$, 1 D.F., $P=0 \cdot 035$; SEASON, Wald $\chi^{2}=7 \cdot 9$, 1 D.F., $P=0.005$; SEASON BY BAIT, Wald $\chi^{2}=3 \cdot 0$, 1 D.F., $P=0 \cdot 084)$. Although the interaction season by bait was not significant, it was on the borderline. However, our data only represent the early stages of the developing impact of baiting the fox population. The interaction was later strongly significant in a larger study (Hegglin et al. 2003).

\section{Arvicola terrestris}

Of 534 voles, 213 were male and 321 female. Of the females, $95(29 \cdot 6 \%)$ showed signs of reproduction. Male voles are either larger than, or the same size as, females (Heske \& Ostfield, 1990). The sexually active females caught all weighed more than $60 \mathrm{~g}$, and their body lengths exceeded $120 \mathrm{~mm}$. Animals below both these thresholds $(71,13 \cdot 1 \%)$ were considered juvenile and omitted from the analysis. Of 469 adult voles, we detected liver lesions in $157(33.5 \%)$ and E. multilocularis infections in $41(8 \cdot 7 \%)$. In 17 of the infected animals, we found 14 to 244400 protoscoleces; this means that $3 \cdot 6 \%$ of the adult voles were actually infective when captured. Most of the lesions not caused by $E$. multilocularis were metacestodes of Taenia taeniaeformis (Strobilocercus fascioloaris) (60, $12 \cdot 8 \%)$. Only $5(1 \cdot 06 \%)$ animals were infected with both E. multilocularis and T. taeniaeformis. Metacestodes of $T$. crassiceps were detected in $4(0 \cdot 8 \%)$ voles, and of these $2(0 \cdot 4 \%)$ were simultaneously infected with $T$. taeniaeformis. Two $T$. crassiceps metacestodes were in subcutaneous cysts, once in the pleural cavity and once in the pericardium. Two lesions $(0 \cdot 4 \%)$ were caused by unidentified Taenia. In $50(10.6 \%)$ voles, the cause of the lesions which were PCR negative for $E$. multilocularis could not be determined.

We found E. multilocularis infected voles in all but 1 of the 10 blocks. Prevalence varied from $3 \cdot 3$ to $16 \cdot 2 \%$ per block. A binary logistic regression with the main factors (BAIT), (AREA), vole sex (SEX), the dichotomous variable (MITE), whether a vole was infected with mites, the three 2-month periods (TIME PERIOD) and, as covariates, body length and transformed spleen mass, revealed no significant effects on E. multilocularis prevalence in voles (all $P>0 \cdot 05$; overall prevalence $8 \cdot 74 \pm 1 \cdot 31 \%$ ).

ANCOVA was used to investigate the influence of the factors: treatment of the foxes (BAIT), vole sex (SEX), the dichotomous variables (INFECTION) and (MITE) and the three 2-month periods (TIME PERIOD) on spleen mass. Body length was entered as a covariate. The analysis also included (AREA), to remove the variance in spleen size due to variation amongst the areas. All 4-way and 3-way interactions were non-significant, and were therefore removed from the final model, as were all non-significant 
Table 1. Analysis of covariance of $\log$ (spleen mass) (overall adjusted $\left.R^{2}=0 \cdot 160\right)$

\begin{tabular}{|c|c|c|c|c|c|}
\hline Source of variation & $\begin{array}{l}\text { Type III Sum } \\
\text { of squares }\end{array}$ & D.F. & $\begin{array}{l}\text { Mean } \\
\text { square }\end{array}$ & $F$ & Significance \\
\hline $\begin{array}{l}\text { BODY LENGTH } \\
\text { (covariate) }\end{array}$ & $0 \cdot 35$ & 1 & $0 \cdot 35$ & $11 \cdot 50$ & $0 \cdot 001$ \\
\hline AREA & $0 \cdot 98$ & 4 & $0 \cdot 25$ & $8 \cdot 07$ & $<0.001$ \\
\hline BAIT & $0 \cdot 24$ & 1 & $0 \cdot 24$ & $8 \cdot 02$ & $0 \cdot 005$ \\
\hline TIME PERIOD & $0 \cdot 08$ & 2 & $0 \cdot 04$ & $1 \cdot 33$ & $0 \cdot 265$ \\
\hline MITE & $<0 \cdot 001$ & 1 & $<0 \cdot 001$ & $0 \cdot 01$ & 0.926 \\
\hline SEX & $<0 \cdot 001$ & 1 & $<0 \cdot 001$ & $0 \cdot 15$ & $0 \cdot 703$ \\
\hline INFECTION & 0.08 & 1 & $0 \cdot 08$ & $2 \cdot 65$ & $0 \cdot 105$ \\
\hline BAIT * TIME PERIOD & $0 \cdot 51$ & 2 & $0 \cdot 25$ & $8 \cdot 31$ & $<0 \cdot 001$ \\
\hline Error & $9 \cdot 98$ & 328 & $0 \cdot 03$ & & \\
\hline
\end{tabular}

2 -way interactions. Spleen mass was positively related to body length $(\beta=0 \cdot 176)$ and varied between areas. Spleen mass decreased with time in the baited blocks only (Table 1; Fig. 2). Furthermore, infected voles had slightly, albeit not significantly, heavier spleens than uninfected voles (residual mass $0 \cdot 069 \pm 0 \cdot 040 v s .-0 \cdot 007 \pm 0 \cdot 010)$, but infection stage (whether protoscoleces were found) had no effect.

\section{Ectoparasitic mites}

For the frequency of mite infestation, there were no significant 4 -way or 3 -way interactions. These were therefore removed from the final model, as were all non-significant 2-way interactions. Infestation was affected significantly by the interaction of BAIT and TIME PERIOD (logistic regression, $\chi^{2}=6.09$, 1 D.F., $P=0 \cdot 048)$; other effects SEX $\left(\chi^{2}=4 \cdot 61\right.$, 1 D.F., $P=0 \cdot 032)$, BAIT $\left(\chi^{2}=5 \cdot 17,1\right.$ D.F., $P=$ 0.023), TIME PERIOD $\left(\chi^{2}=40 \cdot 95,2\right.$ D.F., $P<$ 0.001), INFECTION $\left(\chi^{2}=2 \cdot 40,1\right.$ D.F., $\left.P=0 \cdot 12\right)$, AREA $\left(\chi^{2}=8 \cdot 82,4\right.$ D.F., $\left.P=0 \cdot 066\right)$. In the later two time-periods, voles from baited blocks were more likely to be infested than those from control blocks (May-June $44 \cdot 4 \pm 8 \cdot 4 \%$ vs. $41 \cdot 9 \pm 7 \cdot 6 \%$; JulyAugust $40 \cdot 0 \pm 9 \cdot 1 \%$ vs. $14 \cdot 8 \pm 4 \cdot 58 \%$; SeptemberOctober $74 \cdot 2 \pm 5 \cdot 42 \%$ vs. $62 \cdot 3 \pm 4 \cdot 73 \%$ respectively). Males were more likely to be infested than females $(58 \cdot 3 \pm 4 \cdot 2 \%$ vs. $43 \cdot 8 \pm 3 \cdot 5 \%$ respectively). Infection with E. multilocularis also slightly decreased the frequency of mite infestation (infected $30 \cdot 3 \pm 8 \cdot 1 \%$ vs. non-infected $49 \cdot 1 \pm 2 \cdot 7 \%$ ).

\section{DISCUSSION}

The proportion of fox faecal samples infected with E. multilocularis collected in blocks baited with praziquantel was lower than in control blocks (see also Hegglin et al. 2003). As a consequence it would be expected that fewer eggs of this and presumably of other tapeworms were deposited in baited blocks than in control blocks. Since egg counts in faecal

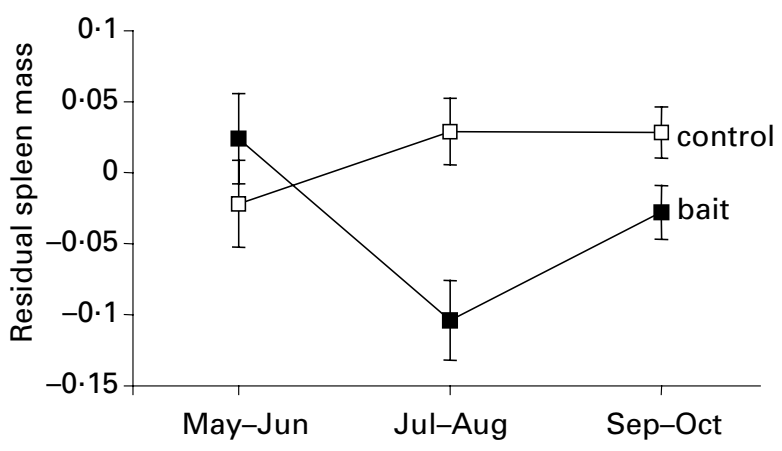

Fig. 2. Mean relative spleen mass \pm s.E. of voles at 3 different time-periods $(n=342)$.

samples of foxes declined in baited blocks, it is likely that the environmental contamination with eggs in these blocks also declined and hence voles in baited zones presumably had a lower contact rate with infective eggs. Although there was no reduction in the infection rate of voles, spleen mass was significantly reduced over time in baited blocks. This was not the case in non-baited control blocks. The frequency with which voles were infested by mites was higher in baited blocks. Although we have no data from before our experiment, these results are most likely due to the treatment. Block allocation was random to prevent any geographical clumping of the blocks of a treatment. It is therefore extremely unlikely that there was any systematic difference between the voles in our treatment groups.

E. multilocularis infection rates in voles are generally low; in geographically extensive studies they are usually below $1 \%$ (Eckert, $2001 \mathrm{~b}$ ). We found prevalences of $3 \cdot 3$ to $16 \cdot 2 \%$ in all but 1 study block, indicating that the study was performed in a highly endemic area. This confirms the existence of locally highly endemic foci (Pétavy \& Deblock, 1983; Gottstein et al. 1996; Hofer et al. 2000). Since infected voles survive for several months, some of the voles trapped were probably infected before or shortly after the beginning of baiting. Parasite eggs may survive for up to 8 months in autumn and winter 
and for up to 3 months in summer (Veit et al. 1995). Therefore, even when final hosts are free of infection, the parasite may survive within a treated area because the voles still come into contact with infective eggs and thus represent sources of new infections.

The average spleen mass of voles in the baited blocks decreased over time, but this did not occur in the control blocks. An increase in spleen mass during infection with $E$. multilocularis, reflecting increased immune defence, has been reported previously (e.g. Ali-Khan, 1978 a, $b$; Playford \& Kamiya, 1992; Fotiadis et al. 1999). Not every contact with $E$. multilocularis leads to infection with the parasite. In early stages of infection the successful establishment of the parasite depends upon the competition between the larval development and the establishment of a protective host immune response (Gottstein, 1992). During this stage of an E. multilocularis infection, a marked activation of the cell-mediated immunity against the parasite occurs (Ali-Khan, 1978b; Playford \& Kamiya, 1992; Fotiadis et al. 1999). E. multilocularis growth appears to be controlled by the host T-cell, and, at least in the early phase of the disease, T-lymphocytes probably play the most important role in the immune response to the parasite (Baron \& Tanner, 1976; Kamiya et al. 1980; Playford \& Kamiya, 1992). The spleen plays an important role in cell-mediated immunity as the storage organ of mature cytotoxic T-cells (Kopp, 1990). In contrast to voles in baited blocks, where the risk of infection seemed to decrease over the season, voles in control blocks had higher spleen mass probably because they were exposed to higher levels of contamination with eggs and because they would have had continuously to maintain higher levels of cell-mediated immunity to combat infection.

We found different frequencies of voles infested with mites in the two treatments. Fewer voles were infested with mites in control blocks in the second and third time-periods; there was no difference in the first period. Voles infected with E. multilocularis also tended to have fewer mites. Since cell-mediated immunity and T-cells play an important role in the immune defence against mites (O’brien et al. 1996), this supports the hypothesis that exposure to one parasite (E. multilocularis) could lead to an activated, general cell-mediated immunity, and consequently to an increased immune response to another parasite (mites). Elevated cell-mediated immunity and the resulting production of T-cells following infections with $E$. multilocularis (Ali-Khan, 1978b; Playford \& Kamiya, 1992; Fotiadis et al. 1999) may thus simultaneously increase immune defence against several challenges. Furthermore, more males harboured mites than females. Gender differences in natural parasitic infections are frequently observed in vertebrates (reviewed by Zuk \& McKean, 1996). These differences are usually attributed to ecological (i.e. different exposure to the parasites) or physiological (i.e. hormonal) differences between the sexes (Zuk \& McKean, 1996; Travi et al. 2002).

This experimental study strongly suggests that the environmental contamination with eggs of $E$. multilocularis, and possibly other tapeworms, influences the immune system in the intermediate host Arvicola terrestris. Further studies are required to understand the longer term consequences of anthelmintic baiting in both the final and the intermediate host(s) of this cestode parasite.

We thank Wolf Blanckenhorn for his help with the statistical analysis and we thank him again and David Hosken, Oliver Martin and two anonymous referees for comments that improved the manuscript. We would also like to thank Isabelle Tanner for her assistance in the lab, Hansueli Ochs for identifying the mites and Marc Wälti for help dissecting the voles.

\section{REFERENCES}

ALI-KHAN, Z. (1974). Host-parasite relationship in echinococcosis. I. Parasite biomass and antibody response in three strains of inbred mice against graded doses of Echinococcus multilocularis cysts. Fournal of Parasitology 60, 231-235.

ALI-KHAN, Z. (1978a). Cellular changes in lymphoreticular tissues of C57/J mice infected with Echinococcus multilocularis cysts. Immunology 34, 831-839.

ALI-KHAN, Z. (1978b). Echinococcus multilocularis cell mediated immune responses in early and chronic alveolar murine hydatiosis. Experimental Parasitology 46, 157-165.

AMMAN, R. \& ECKERT, J. (1995). Clinical diagnosis and treatment of echinococcosis in humans. In Echinococcus and Hydatid Disease (ed. Thompson, R. C. A. \& Lymbery, A. J.), pp. 411-463. CAB International, Walingford.

BARON, R. \& TANNER, C. (1976). The effect of immunosuppression on the secondary $E$. multilocularis infections in mice. International Journal for Parasitology 6, 37-42.

BREITENMOSER, U., MÜLler, U., KAPPELER, A. \& ZANONI, R. G. (2000). The final phase of the rabies epizootic in Switzerland. Schweizer Archiv für Tierheilkunde 142, $447-454$.

Christensen, H. (1985). Urban fox populations in Oslo. Revue d'écologie de la terre et la vie 40, 185-186.

CONTESse, P., HeGGlin, D., GLOOR, S., Bontadina, F., BREITENMOSER, U. \& DePlazes, P. (2004). The diet of urban foxes (Vulpes vulpes) and the availability of anthropogenic food in the city of Zurich, Switzerland. Mammalian Biology 69, 81-95.

DEPlazes, P., ALTHER, P., TANNER, I., THOMPSON, R. C. A. \& ECKERT, J. (1999). Echinococcus multilocularis coproantigen detection by enzyme-linked immunosorbent assay in fox, dog and cat populations. Fournal of Parasitology 85, 115-121.

DePlazes, P., GloOR, s., STIEGER, C. \& HeGGlin, D. (2002). Urban transmission of Echinococcus multilocularis. In Cestode Zoonoses : Echinococcosis and Cysticercosis (ed. Craig, P. \& Pawloski, Z.), pp. 287-297. IOS Press, Amsterdam, Netherlands. 
DEvouge, M. \& ALI-KHAN, Z. (1983). Intraperitoneal murine alveolar hyaditosis: relationship between the size of larval cyst mass, immigrant inflammatory cells, splenomegaly and thymus involution. Tropenmedizin und Parasitologie 34, 15-20.

DINKEL, A., VON NICKISCH-ROSENEGK, M., BILGER, B., MERLI, M., LUCIUS, R. \& ROMIG, T. (1998). Detection of Echinococcus multilocularis in the definitive host: Coprodiagnosis by PCR as an alternative to necropsy. Fournal of Clinical Microbiology 36, 1871-1876.

ECKERT, J. (1998). Echinococcus multilocularis, Echinococcus oligarthrus and Echinococcus vogeli. In Zoonoses : Biology, Clinical Practice, and Public Health Control (ed. Palmer, S. R. \& Simpson, D. I. H.), pp. 689-716. Oxford University Press, Oxford.

ECKERT, J. \& DEPLAZES, P. (1999). Alveolar echinococcosis in humans: the current situation in central Europe and the need for countermeasures. Parasitology Today 15, 315-319.

ECKERT, J., RAUSCh, R. L., GEMMELl, M. A., GIRAdOUX, P., KAMIYA, M., LIU, F-J., SCHANTZ, P. M. \& ROMIG, T. (2001a). Epidemology of Echinococcus multilocularis, Echinococcus vogeli and Echinococcus oligarthrus. In WHO/OIE Manual on Echinococcus in Humans and Animals: A Public health Problem of Global Concern (ed. Eckert, J., Gemmell, M. A., Meslin, F.-X. \& Pawlowski, Z. S.), pp. 164-194. World Organization for Animal Health, Paris.

ECKERT, J., SCHANTZ, P. M., GASSER, R. B., TORGERSON, P. R., BRESSONOV, A. S., MOVSESSIAN, S. O., THAKUR, A., GRIMM, F. \& NIKogossian, M. A. $(2001 b)$. Geographic distribution and prevalence. In WHO/OIE Manual on Echinococcus in Humans and Animals: A Public health Problem of Global Concern (ed. Eckert, J., Gemmell, M. A., Meslin, F.-X. \& Pawlowski, Z. S.), pp. 100-142. World Organization for Animal Health, Paris.

Fotiadis, C., SERGiou, C., Kirou, J., Troupis, T. G., TSElEntis, J., DOUSSAitou, P., GORGOUlis, V. G. \& SECHAS, M. N. (1999). Experimental Echinococcus infection in the mouse model: pericystic cellular immunity reaction and effects on the lymphoid organs of immunocompetent and thymectomized mice. In vivo 13, 541-546.

GiradouX, P., DElatTre, P., HaberT, M., QUERE, J. P., DEBlay, S., DEFAUT, R., DUHAMEL, R., MOISSENET, M. F., SALVI, D. \& DRUCHET, D. (1997). Population dynamics of fossorial water vole (Arvicola terrestris scherman): a land usage and landscape perspective. Agriculture, Ecosystem and Environment 66, 47-60.

Giradoux, P., PRAdier, B., DElatTre, P., DEblay, S., SALVI, D. \& DEFAUT, R. (1995). Estimation of water vole abundance by using surface indices. Acta Theriologica 40, 77-96.

GLOOR, s. (2002). The rise of urban foxes (Vulpes vulpes) in Switzerland and ecological and parasitological aspects of afox population in the recently colonised city of Zurich. Dissertation. University of Zurich, Zurich, Switzerland.

GOTTSTEIN, B. (1992). Echinococcus multilocularis infection: immunology and immunodiagnosis. Advances in Parasitology 31, 321-380.

GOTTSTEIn, B., SAUCY, F., Wyss, C., SIEGENTHALER, M., JACQUIER, P., SCHMITT, M., BROSSHARD, M. \& DEMIERRE, G. (1996). Investigations on a Swiss area highly endemic for
Echinococcus multilocularis. Applied Parasitology 37, 129-136.

HEGGLIN, D., BONTADINA, F., GLOOR, S., MÜLLER, U., BREITENMOSER, U. \& DEPLAZES, P. (2004). Baiting red foxes in an urban area: a camera trap study. Fouranl of wildlife management (in the Press).

HEGGLin, D., WARD, P. I. \& DEPLAZES, P. (2003). Small scale anthelminitc baiting of foxes reduces urban Echinococcus multilocularis egg contamination. Emerging Infectious Diseases 9, 1266-1272.

HESKE, E. J. \& OSTFIELD, R. S. (1990). Sexual dimorphism in size, relative size of testes, and mating systems in north american voles. Fournal of Mammalogy 71, 510-519.

HOFER, S., GLOOR, S., MÜLlER, U., HEGGLIN, D. \& DEPLAZES, P. (2000). High prevalences of Echinococcus multlocularis in urban red foxes (Vulpes vulpes) and voles (Arvicola terrestris) in the city of Zurich. Parasitology 120, $135-142$.

HOUIN, R., DENIEU, M., LIANCE, M. \& PUEL, F. (1982). Arvicola terrestris an intermediate host of Echinococcus multilocularis in France: epidemiological consequences. International fournal for Parasitology 12, 593-600.

JOHN, J. L. (1995). Parasites and the avian spleen. Biological Fournal of the Linnean Society 54, 87-106.

KAMIYA, H., KAMIYA, M., OHBAYASHI, M. \& NOMURA, T. (1980). Studies on the host resistance to infections with Echinococcus multilocularis. 1. Difference of susceptibility of various rodents, especially of congenitally athymic nude mice. Fapanese Fournal of Veterinary Research 29, 87-100.

KOPP, w. C. (1990). The immune functions of the spleen. In The Spleen : Structure, Function and Clinical Significance (ed. Bowdler, A. J.), pp. 261-265. Chapman and Hall, London.

MøLLER-NIELSEN, S. M. (1990). The food of rural and suburban woodland foxes Vulpes vulpes in Denmark. Natura Futlandica 23, 25-32.

NONAKA, N., IIDA, M., YAGI, K., ITO, T., OOI, H. K., OKU, Y. \& KAMIYA, M. (1996). Time course of coproantigen excretion in Echinococcus multilocularis infections in foxes and an alternative definitive host, golden hamsters. International Yournal for Parasitology 26, 1271-1278.

O'BRIEN, R. M., MAY, O., CLARKE, A. H. \& THOMAS, W. R. (1996). Immunologic responses following respiratory sensitization to house dust mite allergens in mice. Immunlogy and Cell Biology 74, 174-179.

PÉTAVy, A. F. \& DEBLOCK, S. (1983). Connaissance du foyer auvergnant d'échinococcose alvéolaire. Annales de Parasitologie Humaine et Comparée 58, 439-453.

PLAYFORD, M. C. \& KAMIYA, M. (1992). Immune-response to Echinococcus multilocularis infection in the house mouse model - A review. Fapanese Fournal of Veterinary Research 40, 113-130.

SCHANTZ, P. M. \& GOTTSTEIN, B. (1986). Echinococcus (hyaditosis). In Immunodiagnosis of Parasitic Diseases (ed. Walls, K. M. \& Schantz, P. M.), pp. 69-107. Academic Press, Orlando, USA.

SCHELLING, U. \& FRANK, w. (1997). Chemotherapy with praziquantel has the potential to reduce the prevalence of Echinococcus multilocularis in wild foxes (Vulpes vulpes). Annals of Tropical Medicine and Parasitology 91, 179-186.

SKARSTEIN, F., FOLSTRAD, I. \& LILJEDAL, S. (2001). Whether to reproduce or not: immune suppression and costs of 
parasites during reproduction in the Arctic charr.

Canadian Fournal of Zoology 79, 271-278.

STEININGER, B. \& BARTH, P. (1999). Microanatomy and function of the spleen. Advances in Anatomy, Embryology and Cell Biology 151, 1-112.

STIEGER, C., HEGGlin, D., SCHWARZENBACH, G., MATHIS, A. \& DEPLAZES, P. (2002). Spatial and temporal aspects of urban transmission of Echinococcus multilocularis. Parasitology 124, 631-640.

SPSS Statistical Package for PC, SPSS PC-Version, 1999, Chicago.

TACKMAN, K., LOSCHNER, U., MIX, H., STAUBACH, C., THULKe, H., ZILlER, M. \& CONRATHS, F. (2001). A field study to control Echinococcus multilocularis-infections of the red fox (Vulpes vulpes) in an endemic focus. Epidemiology and Infection 127, 577-587.
TRAVI, B., OSORIO, Y., MELBY, P., CHANDRASEKAR, B., ARTEAGa, L. \& SARAVIA, N. (2002). Gender is a major determinant of the clinical evolution and immune response in hamsters infected with Leishmania spp. Infection and Immunity 70, 2288-2296.

VEIT, P., BILGER, B., SCHAD, V., SCHÄFER, J., FRANK, W. \& LUCIUS, R. (1995). Influence of environmental factors on the infectivity of Echinococcus multilocularis eggs. Parasitology 110, 79-86.

Weber, J. M. \& Aubry, s. (1993). Predation by foxes, Vulpes vulpes, on the fossorial form of the water vole, Arvicola terrestris Scherman, in western Switzerland. Fournal of Zoology, London 229, 553-559.

ZUK, M. \& McKEAN, K. A. (1996). Sex differences in parasite infections: patterns and processes. International fournal for Parasitology 26, 1009-1023. 